\title{
Fermentation of Milk Using Folate-Producing Lactic Acid Bacteria to Increase Natural Folate Content: A Review
}

\author{
Fenny Amilia Mahara ${ }^{1}$, Lilis Nuraida ${ }^{1,2^{*}}$, Hanifah Nuryani Lioe ${ }^{1}$ \\ ${ }^{1}$ Department of Food Science and Technology, Faculty of Agricultural Engineering and Technology, IPB University (Bogor \\ Agricultural University), Darmaga, Bogor 16680, Indonesia \\ ${ }^{2}$ Southeast Asian Food and Agricultural Science and Technology (SEAFAST) Center, IPB University (Bogor Agricultural University), \\ Bogor 16680, Indonesia
}

Corresponding Author: Lilis Nuraida, PhD, Professor, Department of Food Science and Technology, Faculty of Agricultural Engineering and Technology, IPB University (Bogor Agricultural University), Darmaga Bogor 16680, Indonesia. Tel/Fax: +62251-8626725, Email: Inuraida@gmail.com

Received June 29, 2019; Accepted September 25, 2019; Online Published December 5, 2019

\begin{abstract}
Folate, also known as vitamin B9, is essential in cell metabolism and very important especially for pregnant women and lactating mothers. Natural folate is available in food but it is very unstable. Synthetic folate is generally used as an alternative to meet daily needs due to its stability, even though it has a negative effect causing a variety of metabolic disorders. Some lactic acid bacteria have been reported as being able to synthesize natural folate during the fermentation process. Lactic acid bacteria are the main microorganisms for lactic fermentation such as fermented milk, fruits, and vegetables. Milk is the most nutritious food and contains folate-binding protein, hence it is considered the ideal fermentation medium to increase folate stability during storage. Fermentation of milk with folate-producing lactic acid bacteria can be used as a technique to produce natural folate-rich fermented foods as an attempt to prevent folate deficiency without side effects to the consumers.

Keywords: Lactic Acid Bacteria, Fermentation, Fermented Milk, Folate, Folate-Rich Fermented Food

Citation: Mahara FA, Nuraida L, Lioe HN. Fermentation of milk using folate-producing lactic acid bacteria to increase natural folate content: a review. J Appl Biotechnol Rep. 2019;6(4):129-136. doi:10.29252/JABR.06.04.01.
\end{abstract}

\section{Introduction}

Folate or vitamin B9 is a water-soluble vitamin composed of several conjugated molecules namely pteridine ring, paraaminobenzoic acid (PABA), and glutamic acid. ${ }^{1,2}$ Folate is required for normal cell fission and growth. It functions as a cofactor involved in various metabolic reactions in the body, such as synthesis, repair, DNA methylation reactions; nucleotide synthesis; and amino acid metabolism., ${ }^{3,4}$ Folate is needed in a certain amount, especially during pregnancy and lactating period. The daily recommended intake of folate are $65 \mu \mathrm{g} / \mathrm{d}$ of dietary folate equivalents (DFEs) for 0-6 month infants as adequate intake (AI), $80 \mu \mathrm{g}$ DFE for 7-12 month infants (AI), $150 \mu \mathrm{g}$ DFE for 1-3 year old children as recommended dietary allowance (RDA), $200 \mu \mathrm{g}$ DFE for 4-8 year old children (RDA), $300 \mu \mathrm{g}$ DFE for 9-13 year old children (RDA), $400 \mu \mathrm{g}$ DFE for 14-18 year old teens (RDA), $400 \mu \mathrm{g}$ DFE for adults 19 years old and older (RDA), $500 \mu \mathrm{g}$ DFE for lactating women (RDA), and $600 \mu \mathrm{g}$ DFE for pregnant women (RDA). If folate requirement is not sufficiently met, the body will experience folate deficiency and trigger various diseases such as anemia, neural tube defects, homocysteinemia, cardiovascular disease, and cancer. ${ }^{4,6-9}$

Folate cannot be produced in the body, therefore, it must be obtained from food intake. It is naturally present in various types of food, such as cereals, fruits, vegetables, spices, nuts, eggs, and cheese. ${ }^{10}$ However, natural folate has unstable properties, and its content is easily reduced during washing and processing. ${ }^{11,12}$ Alternatively, folic acid, a synthetic form of folate, is generally chosen as the main source in fulfilling the daily needs as a food fortificant and food supplement due to its stability. ${ }^{13,14}$ However, the metabolic process of folic acid in the body is relatively slow hence the body is not able to completely convert folic acid in large quantities. This results in a substantial accumulation of unmetabolized folic acid in cells. High levels of unmetabolized folic acid in the blood will cause a variety of metabolic disorders, such as masking symptoms of vitamin B12 deficiency, cognitive impairment, reducing the immune system, and cancer. ${ }^{15,16}$ The emergence of health problems related to the use of synthetic folate has prompted many researchers to look for other, more stable, safer and more efficient sources of natural folate.

Lactic acid bacteria (LAB) are known to produce folate both intracellularly and extracellularly. ${ }^{12,17-19}$ Intracellular folate is in the intact cells, while extracellular folate is secreted to the growth medium. Extracellular folate is in the form of monoglutamate, thus it has a higher bioavailability compared to intracellular folate which is in the form of polyglutamate. Polyglutamate requires an enzymatic conjugation process

Copyright $\odot 2019$ The Author(s). This is an open-access article distributed under the terms of the Creative Commons Attribution License (http:// creativecommons.org/licenses/by/4.0), which permits unrestricted use, distribution, and reproduction in any medium, provided the original work is properly cited. 
before being absorbed by the body. ${ }^{12,20,21}$ Therefore, extracellular folate secreted to the media can be effectively and readily used as an alternative source of natural folate.

As a fermentation medium, milk is an ideal matrix because it contains nutrients that are suitable for the growth of $\mathrm{LAB}$ and contains folate-binding proteins that can increase the stability of folate synthesized during fermentation. ${ }^{22-24}$ However, during fermentation, most LAB use folate for their growth, thereby reduce the amount of folate in the product. ${ }^{24}$ The ability of LAB to produce folate depends on fermentation conditions, medium types, the presence of folate precursors, and several other factors. ${ }^{17,20}$ In this review, the utilization of $\mathrm{LAB}$ in increasing natural folate content in fermented milk products that could be used to prevent folate deficiency will be discussed.

Folates: Types, Sources, and Stability

Folate is the generic term of conjugated compounds formed by a pteridine ring linked to PABA and one or more L-glutamates. In nature, folate is in the form of 5-methyltetrahydrofolate (5-MTHF), 5-formyltetrahydrofolate (5-FTHF), 10-formyltetrahydrofolate (10-FTHF), 5,10-methylenetetrahydrofolate, 5,10-methenyltetrahydrofolate (5,10-methenylTHF), 5-formimino tetrahydrofolate, 5,6,7,8-tetrahydrofolate (THF) and dihydrofolate (DHF). The forms of THF and MTHF are the two most important folates for human body. Folate in THF form has a significant role as a cofactor in carbon-1 transfer for DNA synthesis, while the MTHF form is the main form transported and stored in the human body. ${ }^{1,10,25}$

Natural folate is found in various types of plants, animal organs, bacteria, and yeast, and is generally detected in heterogeneous forms, characterized by one unit of carbon atom $(\mathrm{C})$ connected to the positions of N5 $\left(\mathrm{R}_{1}\right)$ and/or N10 $\left(\mathrm{R}_{2}\right)$ (Figure 1a), such as methyl (5-CH3), methylene $(5,10$ $\mathrm{CH} 2$ ), formimino (5- $\mathrm{CH}=\mathrm{NH})$, formyl (5- or $10-\mathrm{CHO}$ ), and methenyl $(5,10-\mathrm{CH})$. In flowering plants or angiosperms, folate is mostly in the forms of methyl (45\%-65\%) and formyl (30-55\%), whereas in vegetables and fruits, it is mostly in the form of 5-MTHF, and a few of 5- and 10-FTHF. In animal organs (liver and kidney), about $40 \%$ of folate is found in the form of methyl derivatives. ${ }^{10,26}$ Meanwhile, the most abundant folate forms in kefir yeast strains are 5-MTHF (43\%-59\%), 5-FTHF (23-38\%), and THF 19\%-23\%. ${ }^{27}$

Among bacteria, LAB and bifidobacteria such as Streptococcus thermophilus, Lactobacillus plantarum, Lactobacillus fermentum, Lactococcus lactis, Bifidobacterium longum, Pediococcus acidilactici, and Weissella confusa, can produce folates naturally in numerous fermented food. ${ }^{12,29-}$ ${ }^{31}$ The dominant forms of folate synthesized by LAB in milk are THF, 5-MTHF, and 5-FTHF (Table 1), while in liquid media, S. thermophilus and L. lactis produce 5-FTHF and 5,10-methenyl-THF. ${ }^{32}$ However, the variety of synthesized folate forms depends on each strain and species of bacteria. ${ }^{1,10,19,25,33-35}$

In addition to the substituent group connected to N5 and/or $\mathrm{N} 10$ of the pteridine ring, natural folate forms also vary in the amount of glutamic acid residue conjugated to pteroic acid, namely monoglutamate or polyglutamate. Most of the folates
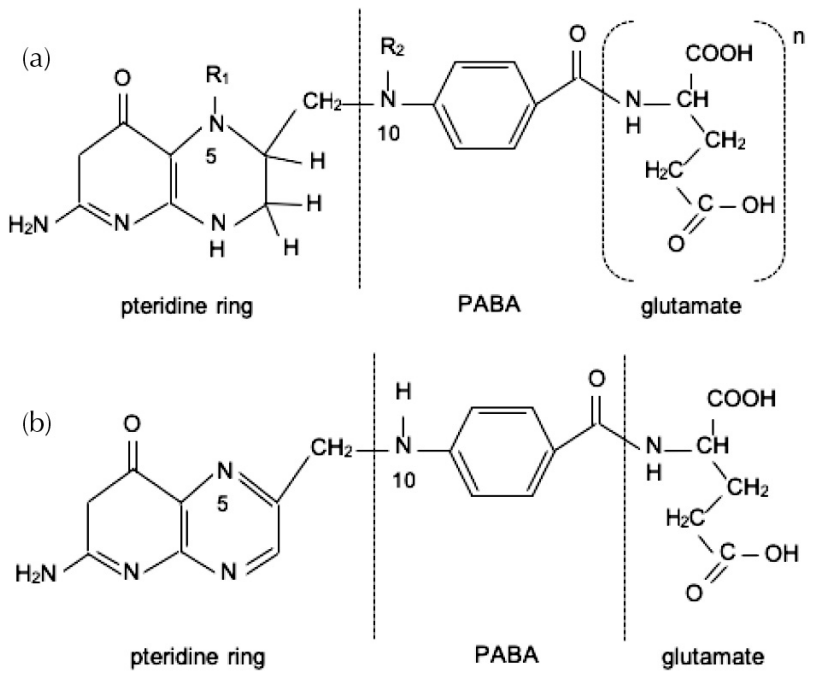

Figure 1. Folate Structure. (a) The main structure of folate with different substituents at $R_{1}$ and $R_{2}{ }^{28}$ (b) The structure of folic acid. ${ }^{10}$

in plants, animals, and microbes are in the reduced form of THF-polyglutamate, where two double bonds of the pteridine ring are reduced, and few are found in the form of free folate (monoglutamate). Monoglutamate folate can be found in milk $(60 \%)$, soybeans $(50 \%)$, and orange juice $(>30 \%)$, whereas polyglutamate forms can be found in cabbage (hexane and heptaglutamate), orange juice (pentaglutamate), liver and kidney (pentaglutamate). ${ }^{2}$

In bacteria, there are two types of synthesized folate, namely intracellular and extracellular folate. Intracellular folate is mostly present in the form of pteroilpentaglutamate ( 5 glutamate residues), whereas extracellular folate tends to be in

Table 1. Forms of Folate Synthesized by LAB in Fermented Milk

\begin{tabular}{|c|c|c|c|c|c|}
\hline \multirow[b]{2}{*}{ Bacterial Species } & \multicolumn{4}{|c|}{ Forms of Synthesized Folate } & \multirow[b]{2}{*}{ Ref. } \\
\hline & THF $^{a}$ & 5-MTHF & $5-\mathrm{FTHF}^{\mathrm{c}}$ & $\begin{array}{c}\text { 5,10-methenyl } \\
\text { THF }^{d}\end{array}$ & \\
\hline S. thermophilus & $t^{e}$ & + & + & $-f^{f}$ & 25 \\
\hline Lactobacillus acidophilus & + & + & + & - & 25 \\
\hline Bifidobacterium longum & + & + & + & - & 25 \\
\hline Lactobacillus bulgaricus & + & + & + & - & 25 \\
\hline S. thermophilus & - & + & - & - & 33 \\
\hline S. thermophilus & + & + & + & - & 36 \\
\hline Lactobacillus bulgaricus & + & + & + & - & 36 \\
\hline Lactobacillus lactis & + & + & + & - & 36 \\
\hline Lactobacillus helveticus & + & + & + & - & 36 \\
\hline $\begin{array}{l}\text { Lactobacillus lactis ssp. } \\
\text { cremoris }\end{array}$ & + & - & - & - & 34 \\
\hline $\begin{array}{l}\text { Lactobacillus lactis ssp. } \\
\text { lactis }\end{array}$ & + & + & - & - & 34 \\
\hline Lactobacillus plantarum & - & + & - & - & 35 \\
\hline Lactobacillus delbrueckii & - & + & - & - & 35 \\
\hline $\begin{array}{l}\text { Bifidobacterium } \\
\text { adolescentis }\end{array}$ & + & - & - & - & 35 \\
\hline $\begin{array}{l}\text { Bifidobacterium } \\
\text { catenulatum }\end{array}$ & + & - & - & - & 35 \\
\hline S. thermophilus & + & + & - & - & 19 \\
\hline
\end{tabular}


the form of pteroilmonoglutamate (1 glutamate residue). The form of synthesized folate by LAB also depends on the species. In Lactococcus lactis species, intracellular folate has the form of tetra-, penta-, to hexaglutamate, and extracellular folate in the form of mono-, di-, to triglutamate. In S. thermophilus species, both intracellular folate and extracellular folate, have mono-, di-, and triglutamate forms. Most of the folate produced by species L. lactis, and other species such as Leuconostoc spp., Propionibacteria spp., and Bifidobacteria spp., are intracellular folates and are not secreted to the media, while $S$. thermophilus species produce extracellular folate which is higher than intracellular folate..$^{21,32,37}$

Based on its variations, natural folate has different stability. The stability order is 5-FTHF> 5-MTHF> THF, studied during fruit and vegetable processing. These folate forms become rapidly unstable due to the longterm contact with water, the presence of oxygen, the low temperature, and the acidic condition. Leaching into the water and the oxidative degradation become two main mechanisms of folate losses. ${ }^{26}$ Furthermore, the oxidation will reduce folate bioavailability due to the conversion of folate into an inactive form, p-aminobenzoyl glutamate, significantly reducing its activity. ${ }^{20}$

Compared to natural folate present in the reduced form, folic acid is in the fully oxidized monoglutamate form. Shown in Figure $1 \mathrm{~b}$, the structure of folic acid is similar to the natural folate form but has fewer hydrogen atoms. This, chemically leads to a more stable form, hence produced synthetically and found in dietary supplements or fortified foods. However, although not naturally found in foodstuffs, some vegetables such as spinach, chickpeas, tomatoes, green beans, and cabbages were reported to have folic acid content in small amounts. The folate degradation during analytical procedures become the likely reason for folic acid being present in plant matrixes. ${ }^{10,26,38}$

Due to the unstable characteristics, natural folate contained in food ingredients is easily damaged or reduced due to the harvesting process, storing, distributing, and processing. ${ }^{12,39-41}$ Therefore, usually synthetic folate in the form of folic acid is chosen as an alternative to meet the demands through fortification or food supplement programs because of its stable characteristic and due to the act, that it is not easily degraded. ${ }^{6,13}$

\section{Folate-Producing Lactic Acid Bacteria}

Lactic acid bacteria are commonly present or used in the fermentation process of various types of food, such as fermented dairy products and its derivatives including yogurt, cheese, kefir, and others; fermented fruits and fermented vegetables. LAB used for fermentation are usually the genus of Lactobacillus, Lactococcus, Leuconostoc, Pediococcus, and Streptococcus. The LAB in milk fermentation can be directly added as a starter culture, or naturally available because milk is a natural habitat of LAB. ${ }^{42}$

During fermentation, LAB convert lactose into lactic acid as the main end product, which increases the acidity and suppresses the growth of pathogenic bacteria, thereby increasing product safety. These bacteria also have a proteolytic activity that can degrade milk protein into components that contribute to the texture and the organoleptic properties of the product ${ }^{43}$ Furthermore, LAB are also known to have the ability to synthesize various groups of vitamin $B$ such as folate (B9), riboflavin (B2), and cobalamin (B12), which can increase the nutritional value of the products. ${ }^{44}$

The group of LAB known to be able to synthesize folate, consist of various genus, species, and strains (Table 2). These bacteria primarily synthesize folate to meet their own needs. $\mathrm{LAB}$ and most of the other organisms (prokaryotic and eukaryotic) require folate cofactors in a reduced form as acceptors or donors of carbon units. This cofactor is involved in various biosynthetic processes such as the formation of methionine, purine, thymine, and various degradation reactions.

\section{Folate Biosynthesis and Secretion by LAB}

The LAB have different ways of fulfilling their folate needs. Some LAB, especially from $S$. thermophilus, Lactobacillus plantarum, and L. lactis species, can synthesize folate through de novo pathway for folate biosynthesis. Other LAB tend to consume folate in the media hence their growth depends on the presence of folate in the media. In fact, the behavior of LAB to meet their folate needs is very different between strains. Several strains of bifidobacteria such as $B$. adolescentis MB 114, B. adolescentis MB 115, and B. pseudocatenulatum MB 116, do not produce folate when folate is available in the media. Several other strains such as B. adolescentis MB 227, B. adolescentis MB 239, and B. pseudocatenulatum MB 237,

Table 2. Species of Folate-Producing LAB

\begin{tabular}{lc}
\hline Species & Literature \\
\hline Streptococcus thermophilus & $17-19,25,31-33,35,37,45,46$ \\
\hline S. lutetiensis, S. infantarius & 12,18 \\
\hline Lactobacillus fermentum & $18,25,47$ \\
\hline L. acidophilus & 18 \\
\hline L. rhamnosus, L. reuteri & $17,25,32,35,45$ \\
\hline L. delbrueckii ssp. bulgaricus & $12,30,32,35,46-50$ \\
\hline L. plantarum & 31,51 \\
\hline L. helveticus & 12,50 \\
\hline L. paraplantarum & 50 \\
\hline L. salivarius & 30 \\
\hline L. sakei, L. coryniformis & 47 \\
\hline L. casei & 52 \\
\hline L. johnsonii & 32 \\
\hline Leuconostoc lactis, Leu. paramesenteroides & $20,31,32,34,48,53$ \\
\hline Lactococcus lactis & 45 \\
\hline Bifidobacterium lactis & 29,54 \\
\hline B. animalis, B. breve & 45,54 \\
\hline B. infantis & 54 \\
\hline B. dentium & 29,54 \\
\hline B. bifidum & $25,29,33,54$ \\
\hline B. longum & $29,35,54$ \\
\hline B. adolescentis, B. catenulatum & 29,54 \\
\hline B. pseudocatenulatum & 50 \\
\hline Pediococcus pentosaceus & 30,55 \\
\hline P. acidilactici & 55 \\
\hline Weissella cibaria & 31 \\
\hline W. paramesenteroides & \\
\hline W. confusa & \\
\hline
\end{tabular}


continued to produce folate even though folate was available in the media. ${ }^{54}$ This shows that the ability of LAB to synthesize folate is dependent on the strains. ${ }^{12,24}$

The folate biosynthesis pathway in microorganisms consists of several parts based on the three main constituents of folate structure namely pteridine, PABA, and glutamate. The pteridine is made from guanosine triphosphate (GTP), synthesized in the purine biosynthetic pathway, whereas PABA comes from chorismate, involved in the same pathway as the aromatic amino acid pathway, glycolysis, pentose phosphate, and the shikimate pathway. ${ }^{21}$ Basically, many microorganisms can synthesize glutamate by the conversion of a-ketoglutarate from glycolytic intermediates. However, most LAB except L. lactis ssp. lactis are reported to be not able to produce glutamate due to the lack of isocitrate dehydrogenase and glutamate dehydrogenase activities, shown to be the main enzymes in the formation of glutamate. ${ }^{56}$ Therefore, the ability of LAB in synthesizing folate is also highly dependent on the availability of glutamate in the media.

In overview, the folate biosynthesis pathway of LAB is catalyzed by nine enzymes, converting GTP to THFpolyglutamate (Figure 2). The biosynthetic process starts with the conversion of GTP to dihydroneopterin, involving the activities of three enzymes, namely GTP cyclohydrolase I, catalyzing the reaction of GTP into dihydroneopterin triphosphate; dihydroneopterin triphosphate pyrophosphohydrolase, converting dihydroneopterin triphosphate to dihydroneopterin monophosphate; and a-specific phosphatase, producing dihydroneopterin. Furthermore, dihydroneopterin is converted to 6-hydroxymethyl-7,8-dihydropterin by dihydroneopterin aldolase, and is further changed to 6-hydroxymethyl-7,8dihydropterin pyrophosphate (DHPPP) by hydroxymethyl dihydropterin pyrophosphokinase. Afterwards, DHPPP fuses with PABA by dihydropteroate synthase enzyme. Incorporating $\mathrm{C}-\mathrm{N}$ bonds from DHPPP to PABA forms dihydropteroate, and is further conjugated with glutamate by dihydrofolate synthase, producing DHF. Moreover, DHF will be reduced by dihydrofolate reductase to the active form of THF. In the end, glutamate residues are added in large amounts by the folylpolyglutamate synthase enzyme to form THF-polyglutamate. ${ }^{21,57}$

The distribution of intracellular and extracellular folate synthesized by $\mathrm{LAB}$ depends on the degree of polyglutamylation or the $\mathrm{pH}$ of growth medium. In L. lactis species, intracellular and extracellular folate distribution only depends on the degree of polyglutamylation and is not influenced by $\mathrm{pH}$. Intracellular folate has a long polyglutamic tail that is more than three glutamate residues $(4,5$, and 6 glutamate residues), whereas extracellular folate has shorter polyglutamate tails namely mono-, di-, to tri-glutamate. Long polyglutamic tails (more than 3 glutamate residues) cannot be transported through cell membranes, so it tends to remain inside cells. Longer glutamate tail increases folate retention in the cell. This is because glutamate has a negatively charged carboxyl group ( $\mathrm{pKa}$ of 4.6) so that the more glutamate residue is bound to the polyglutamic tail, the more negative the folate content is and as a result, increases the folate retention in the cell. ${ }^{32}$ Therefore, the intracellular folate release is highly dependent on cell destruction as it passes through the digestive tract. $^{58}$

In $S$. thermophilus species, intracellular folate and extracellular folate have a short polyglutamic tail, which is not more than three glutamate residues. Thus, the folate distribution does not depend on the degree of polyglutamylation but is dependant on the $\mathrm{pH}$ of the media.
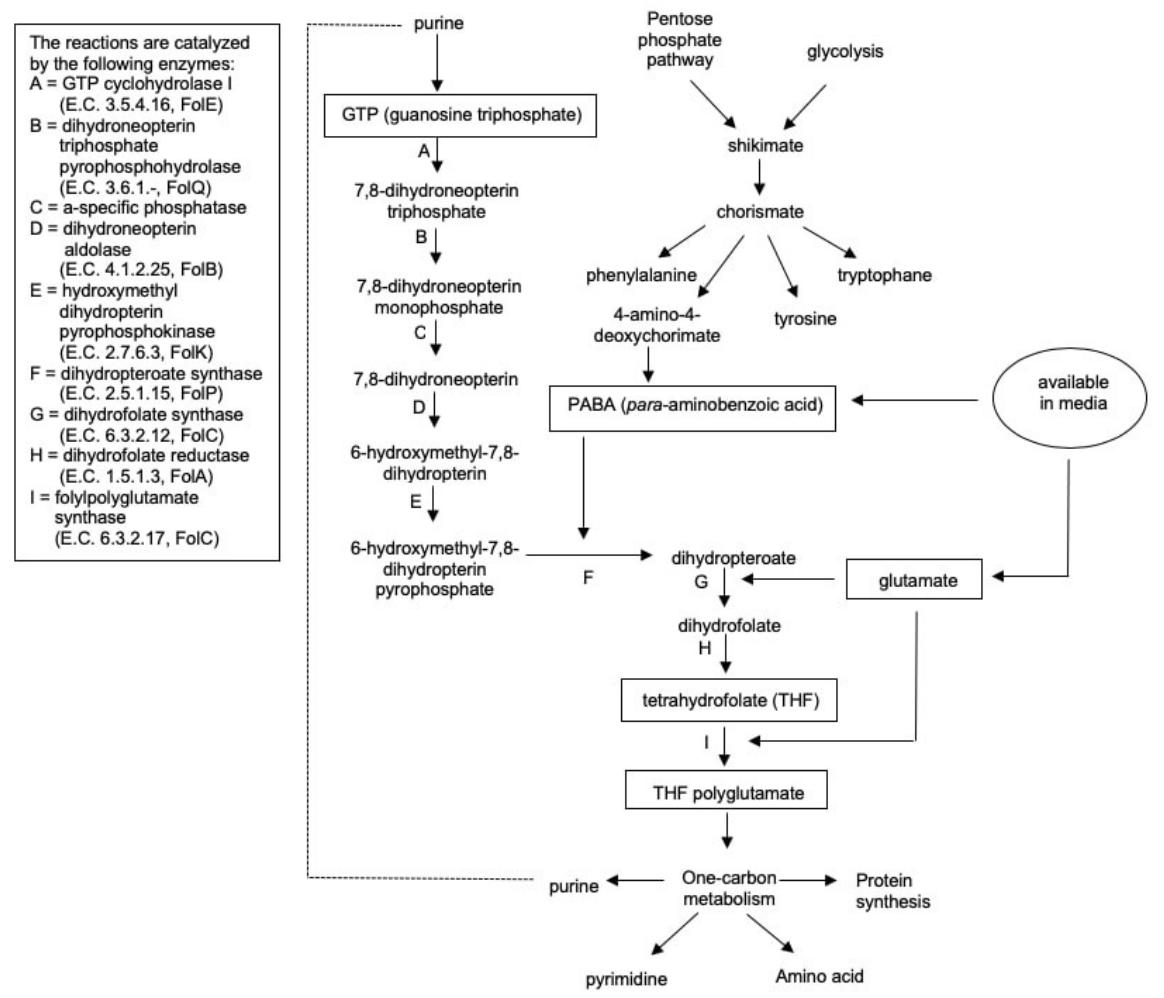

Figure 2. Folate Biosynthesis Pathway in LAB. ${ }^{21,57}$ 
Cells that grow in low $\mathrm{pH}$ will produce higher extracellular folate than cells that grow in high $\mathrm{pH}$. When the media $\mathrm{pH}$ is low, intracellular $\mathrm{pH}$ becomes low too. This condition will cause higher intracellular folate to be protonated and become neutral so that it is easily transported through the cell membrane. In L. lactis, due to the long polyglutamate tail of the intracellular folate (more than three glutamate residues), a decrease in intracellular $\mathrm{pH}$ does not cause intracellular folate protonation so that it cannot be transported across the cell membrane. $^{32}$

Intracellular folate protonation due to low $\mathrm{pH}$ can explain that in certain species of LAB, such as $S$. thermophilus, the $\mathrm{pH}$ of the media greatly determines the ability of LAB to synthesize intracellular and extracellular folate. Low $\mathrm{pH}$ can increase the secretion of extracellular folate, and high $\mathrm{pH}$ can maintain intracellular folate retention. In addition to maintaining intracellular folate retention, high $\mathrm{pH}$ can also increase the ability of LAB to synthesize folate. This is because the enzymes involved in folate biosynthesis in various microorganisms have optimum activity at higher $\mathrm{pH}$ which is between 7.3 and 9.5. Thus, the activity of these enzymes in synthesizing folate can be increased by increasing external $\mathrm{pH}$ which can create more alkaline cell cytosolic conditions. ${ }^{32,35}$ However, even though low media $\mathrm{pH}$ can increase extracellular folate secretion in certain LAB species, this condition will lead to a decrease in extracellular folate concentration. This is due to the fact that extracellular folate has an unstable form so that acidic $\mathrm{pH}$ in the media will cause folate destruction reactions. This shows that the acidity of $\mathrm{pH}$ does not positively correlate with folate production by LAB. ${ }^{35,59}$

The ability of LAB to synthesize folate is also associated with the role of 3 main genes namely folB, folK, and folP. These genes can encode the formation of dihydroneopterin aldolase (DHNA), hydroxymethylpterin pyrophosphokinase (HPPK), and dihydropteroate synthase (DHPS), which are enzymes involved in the formation of THF molecules in de novo folate biosynthesis. ${ }^{19}$ Almost all bacteria with folK and folP genes are assumed to have an ability in synthesizing folate. However, the detection of these genes is not sufficient to estimate its capacity in folate production. ${ }^{12}$

\section{Effect of Precursors on Folate Production by LAB}

In addition to having certain genes, the ability of LAB to produce folate is associated with their ability to synthesize de novo PABA, formed through the shikimate pathway and the conversion of chorismate to PABA. In general, Lactobacillus (except Lactobacillus plantarum) strain can not synthesize de novo PABA hence its ability in producing folate is highly dependent on the availability of PABA in the media, ${ }^{7}$ or instead will consume folate available in the media for its growth. ${ }^{32}$ The L. lactis and S. thermophilus are reported to be able to produce folate, accumulate folate in cells, and secrete it into the media. Both strains can produce folate without PABA supplementation because they have all the genes needed in the shikimate pathway and the conversion of chorismate into PABA. ${ }^{7,20,21,57}$

The production of extracellular folate by LAB such as L. lactis can be increased by adding PABA as a folate precursor. The high amount of PABA can inactivate folypolyglutamate synthetase, which functions in the extension of the polyglutamic tail in folate molecules. When the amount of PABA in the media is increased, the extension of the polyglutamic tail on the folate molecule in the cell becomes inhibited. As a result, monoglutamate folate production elevates. Monoglutamate folate is known to have a lower affinity for most folatedependent enzymes, compared with polyglutamate folate, therefore the retention of monoglutamate folate in cells will decrease. Low folate retention in cells will raise the amount of folate secreted to the media. In other words, adding PABA in the media will promote extracellular folate production, being higher than intracellular folate. ${ }^{20,32,57,60}$

The inactivation enzyme mechanism of folypolyglutamate synthetase is also supported by the results of a study, ${ }^{57}$ where metabolic engineering of overproduction of PABA in folateproducing strain of L. lactis does not result in an increase in total folate synthesized but causes changes in the distribution of folate across the cytoplasmic membrane. The intracellular folate concentration is measured to be relatively lower than extracellular folate secreted to the media.

In addition to PABA, in folate biosynthesis, glutamate as a folate precursor is also needed along with dihydropteroate for the synthesis of DHF, further converted to THF. However, most $\mathrm{LAB}$ are reported to be auxotrophic of glutamate, hence its requirement has to be fulfilled by its availability in the media. The availability of glutamate residue in the media also plays a role in the extension of the polyglutamate tail (THF-polyglutamate) which has high intracellular retention. Therefore, the more glutamate available, the higher intracellular folate is produced and the lower extracellular folate secreted. ${ }^{57}$ However, by the addition of glutamate in a certain concentration $(75 \mu \mathrm{mol} / \mathrm{L})$ in the media, extracellular folate produced by L. lactis becomes doubled when fermented for 8 hours incubation at $37^{\circ} \mathrm{C}$ in milk media. ${ }^{20}$ No literature has reported the mechanism of glutamate in increasing extracellular folate production. Unlike PABA and glutamate, the addition of purine bases in the media (i.e. adenine, guanine, and xanthine), needed for the synthesis of GTP as a folate precursor, can support the growth of LAB but does not affect the folate biosynthesis. Essentially, folate biosynthesis is carried out to meet the growth needs of the bacteria itself. However, the availability of purines in the media can directly replace the role of folate for growth, thus bacteria automatically do not synthesis folate in their cells. ${ }^{57}$

\section{Folate Production in Fermented Milk Products}

Milk is an ideal source of essential nutrients for humans, both children, and adults, for the body's development and maintenance. Milk contains enzymes, proteins (casein, serum proteins, and vitamin-carrying proteins), various minerals (calcium, nickel, selenium, zinc, and iron), various vitamins (vitamin A, riboflavin, niacin, folate, and vitamin C), immunomodulatory, and antimicrobial compounds such as immunoglobulins, lactoperoxidase, and lactotransferrin. ${ }^{61}$ Because of its complex nutritional content, milk has become an important part of daily nutritional intake throughout the globe. ${ }^{51}$ Cow's milk and goat's milk are the most popular 
and widely consumed milk. Cow's milk and goat's milk have different contents of protein, fat, and enzyme which affects the physical and sensory characteristics of the dairy products. Goat milk produces softer curds, higher amounts of small globular fat, and lower allergen properties. Regarding nutrition, cow's milk and goat's milk contain various nutritional components such as protein, calcium, niacin, pantothenic acid, phosphorus, potassium, riboflavin, thiamin, and vitamin $\mathrm{A}$, which are sufficient for the human diet, even in different concentrations. In addition, both cow's milk and goat's milk are not a good source of iron, vitamin $\mathrm{C}$ and D, unless fortified. However, unlike cow's milk, goat's milk contains insufficient levels of vitamin B6, B12, and folate which are not suitable for the growth and development of infants and children. In fact, in 1970, megaloblastic anemia was reported in children exclusively consuming goat's milk, caused by a lack of folic acid and vitamin B12, ${ }^{62}$ therefore, folate fortification was widely applied to goat milk products. ${ }^{63}$ Cow's milk contains a small amount of folate ranging from 20-60 $\mu \mathrm{g} \mathrm{L}^{-1},{ }^{58}$ while goat's milk contains smaller, which is 2-11 $\mu \mathrm{g} \mathrm{L}^{-1}{ }^{64}$ The folate content will be reduced or lost due to the UHT sterilization or heating process. ${ }^{25,36}$ In contrast, both types of milk are reported to contain folate-binding proteins which can increase the stability of folate during storage. Therefore, milk is considered as the most suitable and ideal food medium for folate fortification. ${ }^{22,51,65}$

Milk and dairy products provide $10-15 \%$ of daily folate intake. Some fermented milk products contain a greater amount of folate as a result of its synthesis by LAB during the fermentation process. ${ }^{6}$ However, in some other fermented milk products, LAB could not synthesize folate hence their presence can actually reduce folate levels because they consume available folate for their growth. The ability of LAB to synthesize folate is strain-dependent. ${ }^{12,18,24,42}$ In addition, fermentation conditions such as temperature and incubation time could also affect the production of folate by LAB. ${ }^{20}$ Moreover, $S$. thermophilus is reported to produce maximum folate level at $40-42^{\circ} \mathrm{C}$ after 6 hours of fermentation, ${ }^{19,51}$ while the highest folate level synthesized by Lactobacillus helveticus was achieved at $37^{\circ} \mathrm{C}$ for 18 hours of fermentation. ${ }^{1}$ Lactobacillus plantarum, Lactobacillus delbrueckii, Bifidobacterium adolescentis, and Bifidobacterium catenulatum produced folate at the highest amount at $37^{\circ} \mathrm{C}$ for 10 hours fermentation. ${ }^{35}$ The maximum folate levels synthesized by different LAB in fermented milk products at various temperatures and incubation times are presented in Table 3.

\section{Conclusions}

Increasing folate concentration in fermented milk products using folate producing $\mathrm{LAB}$ can be an alternative in producing natural folate-rich products as an effort to prevent folate deficiency without prompting the side effects. Milk is considered as the best medium for folate production because of its complex nutritional content and the presence of folate binding proteins that can increase the stability of folate. Increasing folate content in fermented milk depends on the LAB used as a starter culture to produce extracellular folate which secreted to the media. The ability to synthesize folate is a special characteristic of the strains of $L A B$, hence the selection of folate-producing strains is critical to obtain $\mathrm{LAB}$ that are able to synthesize folate. Folate production by $\mathrm{LAB}$ is affected by temperature, incubation time, medium composition and the availability of folate precursors such as PABA and glutamate. Therefore, the technological approach to improve the nutritional value of fermented milk has to include optimizing conditions along with a substrate for fermentation.

\section{Authors' Contributions}

All authors equally contributed to the current study.

Conflict of Interest Disclosures

The authors declare they have no conflicts of interest.

Table 3. The Maximum Level of Folate Synthesized by Certain LAB in Fermented Milk Products at Various Temperatures and Incubation Times

\begin{tabular}{|c|c|c|c|c|c|}
\hline Substrate & Bacterial Species & Incubation Temperature $\left({ }^{\circ} \mathrm{C}\right)$ & Incubation Time (h) & Maximum Folate Level $\left(\mathrm{ng} \mathrm{mL}^{-1}\right)$ & Literature \\
\hline \multirow{4}{*}{$\begin{array}{l}\text { Reconstituted non-fat } \\
\text { dry milk }\end{array}$} & S. thermophilus & \multirow{4}{*}{37} & \multirow{4}{*}{6} & $46.7-59.6$ & \multirow{4}{*}{25} \\
\hline & Lactobacillus acidophilus & & & $53.9-63.9$ & \\
\hline & Bifidobacterium longum & & & $75.8-99.2$ & \\
\hline & Lactobacillus bulgaricus & & & $62.8-68.5$ & \\
\hline UHT milk with $1.5 \%$ fat & S. thermophilus & 37 & 12 & 36.9 & 33 \\
\hline \multirow{2}{*}{ Skim milk (5\%) } & Lactobacillus lactis ssp. cremoris & \multirow{2}{*}{37} & \multirow{2}{*}{7} & 12.5 & \multirow{2}{*}{34} \\
\hline & Lactobacillus lactis ssp. lactis & & & 14.2 & \\
\hline \multirow{4}{*}{$\begin{array}{l}\text { Reconstituted non-fat-dry } \\
\text { milk }(12 \%)\end{array}$} & Lactobacillus plantarum & \multirow{4}{*}{37} & \multirow{4}{*}{10} & 25.3 & \multirow{4}{*}{35} \\
\hline & Lactobacillus delbrueckii & & & 110.1 & \\
\hline & Bifidobacterium adolescentis & & & 8.3 & \\
\hline & Bifidobacterium catenulatum & & & 19.4 & \\
\hline \multirow{2}{*}{$\begin{array}{l}\text { Reconstituted non-fat } \\
\text { milk }(10 \%)\end{array}$} & S. thermophilus & 40 & 6 & 47 & \multirow{2}{*}{51} \\
\hline & Lactobacillus helveticus & 37 & 18 & 42 & \\
\hline Skim milk & S. thermophilus & 42 & 6 & $20-80$ & 19 \\
\hline
\end{tabular}




\section{Reference}

1. LeBlanc JG, de Giori GS, Smid EJ, Hugenholtz J, Sesma F. Folate Production by Lactic Acid Bacteria and Other Food Grade Microorganisms. In: Méndez-Vilas A, ed. Communicating Current Research and Educational Topics and Trends in Applied Microbiology. Spain: Formatex; 2007:329-339.

2. Combs GF Jr. The Vitamins: Fundamental Aspects in Nutrition and Health. 3rd ed. New York, USA: Academic Press; 2008.

3. Crider KS, Bailey LB, Berry RJ. Folic acid food fortificationits history, effect, concerns, and future directions. Nutrients. 2011;3(3):370-384. doi:10.3390/nu3030370.

4. Liu Y, Liu YQ, Morita T, Mori M, Sugiyama K. Effect of dietary supplementation with folate on choline deficiency-induced hyperhomocysteinemia in rats. J Nutr Sci Vitaminol (Tokyo). 2012;58(1):20-28. doi:10.3177/jnsv.58.20.

5. Food and Nutrition Board, Institute of Medicine, National Academy of Sciences. Dietary Reference Intakes for Thiamin, Riboflavin, Niacin, Vitamin B6, Folate, Vitamin B12, Pantothenic Acid, Biotin, and Choline. Washington, DC: National Academy Press; 1998:196-305.

6. Iyer R, Tomar SK. Dietary effect of folate-rich fermented milk produced by Streptococcus thermophilus strains on hemoglobin level. Nutrition. 2011;27(10):994-997. doi:10.1016/j. nut.2011.01.003

7. Rossi M, Amaretti A, Raimondi S. Folate production by probiotic bacteria. Nutrients. 2011;3(1):118-134. doi:10.3390/nu3010118.

8. Imbard A, Benoist JF, Blom HJ. Neural tube defects, folic acid and methylation. Int J Environ Res Public Health. 2013;10(9):43524389. doi:10.3390/ijerph10094352.

9. Linares DM, Gomez C, Renes E, et al. Lactic acid bacteria and bifidobacteria with potential to design natural biofunctional health-promoting dairy foods. Front Microbiol. 2017;8:846. doi:10.3389/fmicb.2017.00846.

10. Saini RK, Nile SH, Keum YS. Folates: chemistry, analysis, occurrence, biofortification and bioavailability. Food Res Int. 2016;89(Pt 1):1-13. doi:10.1016/j.foodres.2016.07.013.

11. Delchier N, Ringling C, Le Grandois J, et al. Effects of industrial processing on folate content in green vegetables. Food Chem. 2013;139(1-4):815-824. doi:10.1016/j.foodchem.2013.01.067.

12. Greppi A, Hemery Y, Berrazaga I, Almaksour Z, Humblot C. Ability of lactobacilli isolated from traditional cereal-based fermented food to produce folate in culture media under different growth conditions. LWT. 2017;86:277-284. doi:10.1016/j. Iwt.2017.08.007.

13. Czeizel AE, Dudás I, Vereczkey A, Bánhidy F. Folate deficiency and folic acid supplementation: the prevention of neural-tube defects and congenital heart defects. Nutrients. 2013;5(11):47604775. doi:10.3390/nu5114760.

14. Laiño JE, Juarez del Valle M, Savoy de Giori G, LeBlanc JGJ. Development of a high folate concentration yogurt naturally bioenriched using selected lactic acid bacteria. LWT. 2013;54(1):1-5. doi:10.1016/j.Iwt.2013.05.035.

15. Wright AJ, Dainty JR, Finglas PM. Folic acid metabolism in human subjects revisited: potential implications for proposed mandatory folic acid fortification in the UK. Br J Nutr. 2007;98(4):667-675. doi:10.1017/s0007114507777140.

16. Strickland KC, Krupenko NI, Krupenko SA. Molecular mechanisms underlying the potentially adverse effects of folate. Clin Chem Lab Med. 2013;51(3):607-616. doi:10.1515/cclm-2012-0561.

17. Laiño JE, Leblanc JG, Savoy de Giori G. Production of natural folates by lactic acid bacteria starter cultures isolated from artisanal Argentinean yogurts. Can J Microbiol. 2012;58(5):581588. doi:10.1139/w2012-026.

18. Albuquerque MA, Bedani R, Vieira AD, LeBlanc JG, Saad SM. Supplementation with fruit and okara soybean by-products and amaranth flour increases the folate production by starter and probiotic cultures. Int J Food Microbiol. 2016;236:26-32. doi:10.1016/j.ijfoodmicro.2016.07.008.
19. Meucci A, Rossetti L, Zago M, et al. Folates biosynthesis by Streptococcus thermophilus during growth in milk. Food Microbiol. 2018;69:116-122. doi:10.1016/j.fm.2017.08.001.

20. Divya JB, Nampoothiri KM. Folate fortification of skim milk by a probiotic Lactococcus lactis CM28 and evaluation of its stability in fermented milk on cold storage. J Food Sci Technol. 2015;52(6):3513-3519. doi:10.1007/s13197-014-1406-7.

21. Homayouni Rad A, Yari Khosroushahi A, Khalili M, Jafarzadeh S. Folate bio-fortification of yoghurt and fermented milk: a review. Dairy Sci Technol. 2016;96(4):427-441 . doi:10.1007/s13594-0160286-1.

22. Liang L, Subirade M. Beta-lactoglobulin/folic acid complexes: formation, characterization, and biological implication. J Phys Chem B. 2010;114(19):6707-6712. doi:10.1021/jp101096r.

23. Nygren-Babol L, Jägerstad M. Folate-binding protein in milk: a review of biochemistry, physiology, and analytical methods. Crit Rev Food Sci Nutr. 2012;52(5):410-425. doi:10.1080/10408398 .2010.500499.

24. Laiño JE, Zelaya H, Juárez del Valle M, Savoy de Giori G, LeBlanc JG. Milk fermented with selected strains of lactic acid bacteria is able to improve folate status of deficient rodents and also prevent folate deficiency. J Funct Foods. 2015;17:22-32. doi:10.1016/j. jff.2015.04.055.

25. Lin MY, Young CM. Folate levels in cultures of lactic acid bacteria. Int Dairy J. 2000;10(5):409-413. doi:10.1016/S09586946(00)00056-X

26. Delchier N, Herbig A-L, Rychlik M, Renard CMGC. Folates in fruits and vegetables: contents, processing, and stability. Compr Rev Food Sci Food Saf. 2016;15(3):506-528. doi:10.1111/1541_ 4337.12193.

27. Patring JD, Jastrebova JA, Hjortmo SB, Andlid TA, Jägerstad IM. Development of a simplified method for the determination of folates in baker's yeast by HPLC with ultraviolet and fluorescence detection. J Agric Food Chem. 2005;53(7):2406-2411. doi:10.1021/jf048083g.

28. Revuelta JL, Serrano-Amatriain C, Ledesma-Amaro R, Jiménez A. Formation of folates by microorganisms: towards the biotechnological production of this vitamin. Appl Microbiol Biotechnol. 2018;102(20):8613-8620. doi:10.1007/s00253-0189266-0.

29. D'Aimmo MR, Mattarelli P, Biavati B, Carlsson NG, Andlid T. The potential of bifidobacteria as a source of natural folate. J Appl Microbiol. 2012;112(5):975-984. doi:10.1111/j.13652672.2012.05261.x.

30. Masuda $M$, Ide $M$, Utsumi $H$, Niiro T, Shimamura $Y$, Murata M. Production potency of folate, vitamin $\mathrm{B}(12)$, and thiamine by lactic acid bacteria isolated from Japanese pickles. Biosci Biotechnol Biochem. 2012;76(11):2061-2067. doi:10.1271/bbb.120414.

31. Pacheco Da Silva FF, Biscola V, LeBlanc JG, Gombossy de Melo Franco BD. Effect of indigenous lactic acid bacteria isolated from goat milk and cheeses on folate and riboflavin content of fermented goat milk. LWT. 2016;71:155-161. doi:10.1016/j. Iwt.2016.03.033.

32. Sybesma $W$, Starrenburg $M$, Tijsseling L, Hoefnagel $M H$, Hugenholtz J. Effects of cultivation conditions on folate production by lactic acid bacteria. Appl Environ Microbiol. 2003;69(8):45424548. doi:10.1128/aem.69.8.4542-4548.2003.

33. Holasová M, Fiedlerová $\mathrm{V}$, Roubal $\mathrm{P}$, Pechačová M. Biosynthesis of folates by lactic acid bacteria and propionibacteria in fermented milk. Czech J Food Sci. 2004;22(5):175-181. doi:10.17221/3421CJFS.

34. Gangadharan D, Sivaramakrishnan S, Pandey A, Nampoothiri KM. Folate-producing lactic acid bacteria from cow's milk with probiotic characteristics. Int J Dairy Technol. 2010;63(3):339-348. doi:10.1111/j.1471-0307.2010.00590.x.

35. Padalino $M$, Perez-Conesa $D$, López-Nicolás $R$, FrontelaSaseta C, Ros-Berruezo G. Effect of fructooligosaccharides and galactooligosaccharides on the folate production of some 
folate-producing bacteria in media cultures or milk. Int Dairy J. 2012;27(1):27-33. doi:10.1016/j.idairyj.2012.06.006.

36. Sanna MG, Mangia NP, Garau G, et al. Selection of folateproducing lactic acid bacteria for improving fermented goat milk. Ital J Food Sci. 2005;17(2):143-154.

37. Iyer R, Tomar SK, Mohanty AK, Singh P, Singh R. Bioprospecting of strains of Streptococcus thermophilus from Indian fermented milk products for folate production. Dairy Sci Technol. 2011;91(2):237246. doi:10.1007/s13594-011-0011-z.

38. MadzivaH,KailasapathyK,PhillipsM.Alginate-pectinmicrocapsules as a potential for folic acid delivery in foods. J Microencapsul. 2005;22(4):343-351. doi:10.1080/02652040500100931.

39. Food and Agriculture Organization of the United Nations (FAO), World Health Organization (WHO). Vitamin and mineral requirements in human nutrition. 2nd ed. Bangkok, Thailand: FAO, WHO; 1998.

40. Frommherz L, Martiniak Y, Heuer T, Roth A, Kulling SE, Hoffmann I. Degradation of folic acid in fortified vitamin juices during long term storage. Food Chem. 2014;159:122-127. doi:10.1016/j. foodchem.2014.02.156.

41. Pérez-Masiá R, López-Nicolás R, Periago MJ, Ros G, Lagaron JM, López-Rubio A. Encapsulation of folic acid in food hydrocolloids through nanospray drying and electrospraying for nutraceutical applications. Food Chem. 2015;168:124-133. doi:10.1016/j. foodchem.2014.07.051.

42. Gemechu T. Review on lactic acid bacteria function in milk fermentation and preservation. Afr J Food Sci. 2015;9(4):170-175. doi:10.5897/AJFS2015.1276.

43. Shiby VK, Mishra HN. Fermented milks and milk products as functional foods--a review. Crit Rev Food Sci Nutr. 2013;53(5):482496. doi:10.1080/10408398.2010.547398.

44. LeBlanc JG, Laiño JE, del Valle MJ, et al. B-group vitamin production by lactic acid bacteria--current knowledge and potential applications. J Appl Microbiol. 2011;111(6):1297-1309. doi:10.1111/j.1365-2672.2011.05157.x.

45. Crittenden RG, Martinez NR, Playne MJ. Synthesis and utilisation of folate by yoghurt starter cultures and probiotic bacteria. Int J Food Microbiol. 2003;80(3):217-222 . doi:10.1016/s01681605(02)00170-8.

46. Ibrahim GA, El-Sayed HS, El-Shafei K, Sharaf OM. Riboflavin and folate production in different media using encapsulated Streptococcus thermophilus and Lactobacillus plantarum. Middle East J Appl Sci. 2015;5(3):663-669.

47. $\mathrm{Wu} \mathrm{Z}, \mathrm{Wu}$ J, Cao P, et al. Characterization of probiotic bacteria involved in fermented milk processing enriched with folic acid. J Dairy Sci. 2017;100(6):4223-4229. doi:10.3168/jds.2017-12640.

48. Nor NM, Mousavi SS, Mohamad R, Ling FH, Rahim RA. Screening of Lactic Acid Bacteria for Folic Acid Production from Various Sources. In: 30th Symposium of Malaysian Society for Microbiology; 2008; Malaysia..

49. Hugenschmidt S, Schwenninger SM, Lacroix C. Concurrent high production of natural folate and vitamin B12 using a co-culture process with Lactobacillus plantarum SM39 and Propionibacterium freudenreichii DF13. Process Biochem. 2011;46(5):1063-1070. doi:10.1016/j.procbio.2011.01.021.

50. 50 Turpin W, Humblot C, Guyot JP. Genetic screening of functional properties of lactic acid bacteria in a fermented pearl millet slurry and in the metagenome of fermented starchy foods. Appl Environ Microbiol. 2011;77(24):8722-8734. doi:10.1128/aem.05988-11.

51. Kundu S, Deep S. Comparative studies on folate production and parameter optimization in fermented milk from yoghurt starter culture. Int J Eng Sci Res Technol. 2014;3(12):653-660.

52. Nor NM, Mohamad R, Foo HL, Rahim RA. Improvement of folate biosynthesis by lactic acid bacteria using response surface methodology. Food Technol Biotechnol. 2010;48(2):243-250.

53. Divya JB, Nampoothiri KM. Encapsulated Lactococcus lactis with enhanced gastrointestinal survival for the development of folate enriched functional foods. Bioresour Technol. 2015;188:226-230. doi:10.1016/j.biortech.2015.01.073.

54. Pompei A, Cordisco L, Amaretti A, Zanoni S, Matteuzzi D, Rossi M. Folate production by bifidobacteria as a potential probiotic property. Appl Environ Microbiol. 2007;73(1):179-185. doi:10.1128/aem.01763-06.

55. Deatraksa J, Sunthornthummas S, Rangsiruji A, Sarawaneeyaruk S, Suwannasai N, Pringsulaka O. Isolation of folate-producing Weissella spp. from Thai fermented fish (Plaa Som Fug). LWT. 2018;89:388-391. doi:10.1016/j.Iwt.2017.11.016.

56. Lapujade $P$, Cocaign-Bousquet $M$, Loubiere $P$. Glutamate biosynthesis in Lactococcus lactis subsp. lactis NCDO 2118. Appl Environ Microbiol. 1998;64(7):2485-2489.

57. WegkampA, van OorschotW, deVos WM, Smid EJ. Characterization of the role of para-aminobenzoic acid biosynthesis in folate production by Lactococcus lactis. Appl Environ Microbiol. 2007;73(8):2673-2681. doi:10.1128/aem.02174-06.

58. LeBlanc JG, Laiño JE, del Valle MJ, de Giori GS, Sesma F, Taranto MP. B-group vitamins production by probiotic lactic acid bacteria. In: Mozzi F, Raya RR, Vignolo GM, eds. Biotechnology of Lactic Acid Bacteria. New Jersey, US: John Wiley Sons, Ltd; 2015:279296. doi:10.1002/9781118868386.ch17.

59. Paine-Wilson B, Chen TS. Thermal destruction of folacin: effect of $\mathrm{pH}$ and buffer ions. J Food Sci. 1979;44(3):717-722. doi:10.1111/j.1365-2621.1979.tb08484.x.

60. Sybesma W, Van Den Born E, Starrenburg M, et al. Controlled modulation of folate polyglutamyl tail length by metabolic engineering of Lactococcus lactis. Appl Environ Microbiol. 2003;69(12):7101-7107. doi:10.1128/aem.69.12.7101-7107.2003.

61. Ismail MM. Fermented milk and protection from cardiovascular disease. Nutr Food Sci Int J. 2017;3(2):555608. doi:10.19080/ NFSIJ.2017.03.555609.

62. Clark S, Mora Garcia MB. A 100-year review: advances in goat milk research. J Dairy Sci. 2017;100(12):10026-10044. doi:10.3168/ jds.2017-13287.

63. Díaz-Castro J, Lisbona F, Moreno M, Alférez MJM, Campos MS, López-Aliaga I. Influence of goat milk on iron deficiency anemia recovery. Int J Dairy Sci Process. 2015;2(1):7-11. doi:10.19070/2379-1578-150003.

64. Jenness R. Composition and characteristics of goat milk: review 1968-1979. J Dairy Sci. 1980;63(10):1605-1630. doi:10.3168/ jds.S0022-0302(80)83125-0.

65. Zenebe T, Ahmed N, Kabeta T, Kebede G. Review on medicinal and nutritional values of goat milk. Academic Journal of Nutrition. 2014;3(3):30-39. 